\title{
Inclusión, escuela y conocimientos: Elementos para un análisis materialista del programa Conectar Igualdad en las escuelas argentinas
}

\author{
Inclusão, escola e conhecimento: elementos para \\ uma análise materialista do programa Connect \\ Equality em escolas argentinas
}

\section{Inclusion, school and knowledges: Elements for a materalistic approach of Conectar Igualdad Program in Argentinian schools}

Mariano Zukerfeld Conicet/ e-TCS/ Centro CTS/ UM, Argentina

Autor referente: marianozukerfeld@e-tcs.org

Historia Editorial

Recibido: 19/06/2017

Aceptado: 25/10/2017

\section{RESUMEN}

Este artículo indaga desde una perspectiva materialista cognitiva, respecto de los diversos flujos de conocimientos que circulan en las instituciones escolares beneficiarias del Programa Conectar Igualdad en Argentina. En particular, se pregunta ¿cuáles son las transformaciones, beneficios y obstáculos relativos a la circulación de conocimientos que los distintos actores identifican en los niveles subjetivo, tecnológico e intersubjetivo? ¿Qué respuestas de política pública son necesarias 0 factibles ante tal diagnóstico? Metodológicamente, se basa en un trabajo de campo realizado en 2015 que incluyó, entre otras fuentes primarias, encuestas representativas nacionales a 3183 alumnos y 342 docentes.

Palabras clave: Programa Conectar Igualdad; Capitalismo informacional; Materialismo cognitivo; Inclusión digital 


\section{RESUMO}

Este artigo explora a partir de uma perspectiva materialista cognitiva, em relação aos diferentes fluxos de conhecimento que circulam nas escolas beneficiárias do Programa Conectar Igualdad na Argentina. Em particular, quais são as transformações, benefícios e obstáculos relacionados à circulação do conhecimento que os diferentes atores identificam nos níveis subjetivo, tecnológico e intersubjetivo? Quais as respostas das políticas públicas necessárias ou viáveis em face desse diagnóstico? Metodologicamente, baseia-se em um trabalho de campo realizado em 2015 que incluiu, entre outras fontes primárias, pesquisas nacionais representativas de 3183 alunos e 342 professores.

Palavras-chave: Programa Conectar Igualdad; Capitalismo informativo; Materialismo cognitivo; Inclusão digital

\section{ABSTRACT}

This paper tackles, from a cognitive materialist perspective, the various knowledge flows that circulate within education institutions covered by Conectar Igualdad Program in Argentina. Specifically, it addresses, what are the transformations, advantages and limitations related to knowledge flows that different actors find in the subjective, technological and intersubjective bearers? What kind of public policies are desirable to face those challenges? Methodologically, the paper draws on a fieldwork conducted in 2015 which included national representative surveys completed by 3183 students and 342 teachers.

Keywords: Conectar Igualdad Program; Informational capitalism; Cognitive materialism; Digital inclusion

\section{Introducción}

[ n el Capitalismo informacional (Castells, 1999), la inclusión social no está tan sólo relacionada con la participación en las redes de producción y distribución de conocimientos, sino específica e inexorablemente con aquellos cuyo soporte es la información digital. Por su parte, la educación formal, particularmente la educación pública, frecuentemente ha sido un ámbito privilegiado para políticas que buscan la inclusión social. En los últimos años, además, se viene intentando que la institución escolar adopte, o al menos dialogue con las tecnologías digitales. En la intersección de estas vocaciones de inclusión y digitalización es que encontramos a los llamados planes 1 a 1, que suelen asociarse con la distribución una computadora para cada 
alumno/a. El Programa Conectar Igualdad $(\mathrm{PCl})$ es el más grande del mundo en esta modalidad -en términos de la cantidad de computadoras entregadas-, y sus impactos en la producción y circulación de flujos cognitivos en la sociedad argentina son objeto de debate, tanto en su aspecto relativo a la inclusión digital de los hogares como en cuanto a su faz orientada a la digitalización de la institución escolar. Específicamente, en lo relativo a la materialización del plan en la institución escolar, la literatura ha identificado usualmente cuatro actores clave (alumnos, docentes, directivos y referentes técnicos escolares, en adelante RTE), de los que han recogido prácticas y representaciones. Así, se ha avanzado en la caracterización de la dimensión subjetiva o individual. Sin embargo, se ha prestado una atención escasa o relativamente carente de sistematicidad a las interacciones de ese nivel subjetivo con las otras dos dimensiones relevantes del objeto socio-técnico bajo estudio: la dimensión específicamente tecnológica (con una ausencia de desagregación entre las capas de infraestructura, hardware, software y contenidos, tratando a "las netbooks" como ente técnico monolítico) y la dimensión intersubjetiva o social (sin estudiar en detalle los impactos concretos del $\mathrm{PCl}$ en valores, normas, organización, redes de reconocimiento y lenguajes).

De este modo, la envergadura y la complejidad de las transformaciones en curso en la institución escolar (que incluyen pero exceden a los aspectos educativos) imponen limitaciones a los análisis que no las abordan como un sistema de circulación de flujos cognitivos en el que se anudan los aspectos subjetivos, intersubjetivos y tecnológicos. Por ejemplo, es usual encontrar relatos acerca de que no se utilizan las netbooks en las aulas, y que esto sea percibido como un problema por distintos actores. Sin embargo, este tipo de diagnóstico es insuficiente: ¿En qué medida se debe a la disconformidad de los alumnos con la ausencia de conectividad (infraestructura)? ¿En qué proporción a la relación de los docentes con la capa del software? ¿Y qué rol tiene el vínculo entre el hardware que no funciona y el referente técnico escolar? 
Asimismo, los trabajos de campo muestran profundas transformaciones en la modalidad organizacional (en muchos casos variando la disposición áulica, pero también el poder relativo de los actores e incluso la circulación de informaciones plasmándose a veces a través de grupos de Facebook que vertebran la comunidad educativa-), las normas (relativas a la cantidad y calidad del uso permitido de los distintos niveles de la dimensión tecnológica), los valores (por ejemplo, la valoración de la habilidad de buscar información frente a la memorización), los lenguajes (nuevo vocabulario que genera renovadas inclusiones y exclusiones) y las redes de reconocimiento (por ejemplo, las conformación de grupos en relación al tipo de vínculo que tienen con las tecnologías digitales).

Es por ello que partimos del siguiente problema de investigación:

¿Cómo interactúan las dimensiones subjetiva, intersubjetiva y tecnológica en la institución escolar beneficiaria del $\mathrm{PCI}$ ? En particular, ¿cuáles son las transformaciones, beneficios y obstáculos relativos a la circulación de conocimientos que los distintos actores identifican en los niveles subjetivo, tecnológico e intersubjetivo? ¿Qué respuestas de política pública son necesarias o factibles ante tal diagnóstico?

Este artículo presenta un brevísimo resumen de los resultados de una investigación financiada por el CIECTI-Mincyt y realizada durante 2015 por un consorcio integrado por el equipo e-TCS del Centro CTS de la Universidad Maimónides y el equipo del Dr. Sebastián Benítez Larghi de la Universidad Nacional de la Plata, que intentó responder a esas preguntas. Es importante señalar que la brevedad de este artículo impone diversas limitaciones, entre ellas, las relativas a la presentación de los datos que respaldan las afirmaciones que se hacen aquí y la discusión pormenorizada de la literatura específica. Tanto la inclusión de cuadros y figuras como un análisis detallado de las coincidencias y limitaciones con las contribuciones previas hubiera hecho imposible efectuar una presentación general como la que se intenta y nos hubiese 
obligado enfocarnos en alguna dimensión específica. El lector interesado, no obstante, puede consultar el informe final de dicha investigación.

\section{Marco Teórico}

Tanto los planes " 1 computadora 1 alumno" o " 1 a 1 " en general como el $\mathrm{PCl}$ en particular han dado lugar a una creciente producción de literatura académica (Consejo Federal de Educación, 2010; Gvirtz y Necuzzi, 2011; Fontdevila, 2011; Sagol, 2011; Lugo y Kelly, 2011; Grebnicoff, 2011; De La Fuente, Guérin, Güida, Eugenio y Pérez Antelaf, 2011; Dussel, 2011, 2014; Ministerio de Educación, 2012, 2011; Gruszycki, Oteiza y Maras, 2012; Alessio et al, 2012; Bogado, 2013; Lago Martínez, Marotias y Amado, 2012; Lucangioli, 2013; Nosiglia y Norbis, 2013; Spinazzola y Thüer, 2013; Vacchieri, 2013; Ros, et al., 2014; Casablancas, 2014; Verdún y Gutiérrez, 2014; Rivoir, 2014; Benítez Larghi, 2013; Benítez Larghi et al., 2014, 2015). Sin embargo, los valiosos trabajos dedicados a uno o varios de esos ejes presentan por lo general alguna de las siguientes limitaciones.

La primera y principal de ellas es que, usualmente, se reduce el análisis del $\mathrm{PCl}$ a la relación de los actores sociales con "las netbooks", entendidas como un ente tecnológico monolítico. Más allá de comentarios marginales, no se han hecho estudios sistemáticos de la dimensión propiamente tecnológica: se ha hablado de infraestructura, hardware, pero mucho menos de software, y contenidos. En segundo lugar, y en el mismo sentido pero enfatizando el aspecto a veces llamado "social", no hay por lo general marcos sistemáticos respecto de cómo estudiar los distintos flujos de conocimientos intersubjetivos (valores, normas, lenguajes, redes de reconocimiento, aspectos organizacionales) que moviliza el $\mathrm{PCl}$ en la institución escolar.

La tercera limitación es en alguna medida la base de las primeras: los estudios mencionados en general se basan en enfoques del campo de la educación, la 
sociología y otras disciplinas, pero sólo en alguna excepción recurren a perspectivas del campo de los estudios sociales de la ciencia, la tecnología y la innovación (CTS o $\mathrm{CTI}$ ), que ofrece diversas herramientas respecto de cómo analizar la circulación de flujos de conocimientos en la interacción entre actores sociales y tecnologías en marcos institucionales (dos excepciones: Dussel, 2014; Da Silva Ramos y López Gallego, 2014). Por último, son escasísimos los estudios académicos cuantitativos basados en muestras representativas nacionales

Ante esto, nuestra investigación se basó en analizar flujos de conocimientos en base a sus distintos soportes materiales. Eso se basa en una perspectiva que denominamos materialismo cognitivo (para un desarrollo, vid. Zukerfeld, 2017). Así, la institución escolar como sistema aparece anudando tres dimensiones de conocimientos: subjetivos o individuales, intersubjetivos o colectivos y objetivados en tecnologías (Zukerfeld, 2014b).

Para estudiar esos tres niveles, la herramienta principal que utilizaremos es la de auscultar las representaciones sociales (Jodelet, 1986) de algunos actores (alumnos, docentes, directivos y referentes técnicos escolares).

La dimensión subjetiva refiere a las ideas acerca de los beneficios y problemáticas asociados con la dimensión tecnológica a nivel individual. Es importante aclarar que el análisis de la dimensión subjetiva supone las representaciones de los cuatro grupos de actores sobre sí mismos y los otros actores, es decir, como fuentes de información, proveedores de representaciones, y objeto de esa información, representados.

Por su parte, la dimensión intersubjetiva o colectiva refiere a conocimientos que se apoyan en los vínculos entre los sujetos humanos que los preexisten y tienen una vida razonablemente autónoma de la de todo individuo particular. La literatura de las ciencias sociales señala al menos cinco clases: Lingüísticos (se basan en la capacidad colectiva humana de codificar, decodificar y crear códigos intersubjetivos); Redes de reconocimiento (refieren a la triple operación de reconocer a otros, ser reconocido y 
autoreconocerse en una serie de lazos o vínculos); Organizacionales (expresan la división del trabajo en cualquier clase de tarea grupal); Normativos (aluden a la internalización intersubjetiva de ciertas pautas de conducta explícitas o implícitas); Valorativos (designan a las creencias axiológicas) (Zukerfeld, 2017, 2014b). Esos cinco tipos de conocimientos intersubjetivos son extremadamente relevantes para comprender la dinámica de la institución escolar de un modo que no empobrezca las interacciones socio-técnicas reduciéndolas a relaciones entre sujetos individuales y tecnologías.

En cuanto a la dimensión tecnológica, diversos trabajos han propuesto una división en capas para analizar las tecnologías digitales (Lessig, 1999; Vercelli, 2006; Zukerfeld, 2014a) que ha sido específicamente aplicada a los planes 1 a 1 (Dughera, 2013a, 2013b). Esta dimensión incluye la distinción entre las capas de infraestructura (todo lo relativo al suministro eléctrico, conectividad a internet), hardware (las computadoras propiamente dichas), software (desde los sistemas operativos hasta las aplicaciones de las páginas web) y contenidos (textos, audios, imágenes). Esta separación es importante porque estas capas cuentan con rasgos técnicos, costos económicos y regulaciones jurídicas muy divergentes. Asimismo, evita la usual ausencia de distinción entre las capas del software y los contenidos respecto de la del hardware.

De este modo el objetivo general de la investigación fue el de explicar los modos de interacción entre las dimensiones subjetiva, intersubjetiva y tecnológica en las instituciones escolares beneficiarias del PCl con el propósito de ofrecer un diagnóstico preciso, capaz de resultar en recomendaciones de políticas públicas.

\section{Metodología}

Metodológicamente, nuestra investigación tomó como unidad de análisis principal a los alumnos de las escuelas secundarias beneficiarias del PCI. Para llevar adelante el estudio fue seleccionada una muestra representativa de escuelas secundarias urbanas 
de todo el país. En cada una de ellas se han recogido datos recurriendo a fuentes de información primarias tanto cuantitativas como cualitativas.

Así, se encuestó a 3183 alumnos (de tercero y quinto año) y 342 docentes, y se realizaron 8 observaciones no participantes, 32 entrevistas no estructuradas a informantes clave (docentes, directivos y en adelante RTE) y 8 focus groups. El presente artículo sólo incluye algunos de los datos cuantitativos. Por motivos de espacio no hemos podido incluir numerosos datos cuantitativos relevantes ni los resultados del trabajo cualitativo.

Para la selección de la muestra se confeccionaron estratos en base a un conjunto de dimensiones que respondían, en última instancia, a dos variables de los hogares: nivel de acceso a infraestructura y nivel de acceso a tecnologías digitales. Así, en adelante, cuando nos refiramos a los estratos con altos o bajos niveles de acceso, estaremos aludiendo básicamente a estas dos variables.

\section{Resultados}

A continuación se presentan algunos de los principales hallazgos de la investigación, organizados en torno a las dimensiones relativas a la materialidad de los conocimientos involucrados.

\subsection{Generalidades sobre la valoración del PCI}

Uno de los hallazgos más fuertes de la investigación refiere a aquello que denominamos sinécdoque tecnológica. Es decir, la tendencia mayoritaria especialmente entre los alumnos - a asociar el PCI a una sola parte de él, la netbook, siendo que se trata en realidad de una política compleja que incluye no sólo conocimientos objetivados como hardware, sino también software, contenidos, normas, lenguajes, aspectos organizacionales, valores y saberes procedimentales. Además, se encuentra que este fenómeno de sinécdoque es mayor en los estudiantes del estrato con niveles de acceso más altos (y más aún entre las mujeres) y desciende 
claramente en los estratos menos favorecidos.

En este sentido se ha señalado que mientras el PCl genera cierta apatía (que incluye a la sinécdoque tecnológica) en los sectores con mayores niveles de acceso, entre los sectores con menores niveles de acceso no sólo es relevante, sino que lo es específicamente en términos educativos. Esta cuestión es de notable trascendencia ya que en diversos estudios sobre modelos 1 a 1 predomina la idea de que éstos han contribuido a la inclusión digital de las poblaciones por sobre la de las transformaciones educativas.

Si bien entre los docentes el $\mathrm{PCl}$ aparece fuertemente asociado a los problemas técnicos que trae aparejado (roturas, bloqueos de netbooks, falta de acceso a Internet), también aparece significativamente valorado como un dinamizador del capital social, del incremento de la densidad comunicativa. El género de los docentes parece ser una variable importante en este aspecto. Podría conjeturarse que los docentes varones harían usos comunicativos con los alumnos superiores a los que hacen las docentes mujeres. Esto, a su vez, está relacionado con las transformaciones en los conocimientos de soporte intersubjetivo organizacionales: este tipo de comunicación puede establecerse por fuera del tiempo y espacio estrictamente escolares. Por el contrario, entre las mujeres prevalecen asociaciones que marcan una mayor distancia con el PCl: la sinécdoque tecnológica mencionada (que también era superior entre las alumnas mujeres) y las capacitaciones. Éstas, en tanto que obligación u oferta, en cualquier caso vinculan al plan con fenómenos ajenos a la dinámica cotidiana de la escuela.

En cuanto a la valoración general del $\mathrm{PCl}$, en términos generales, los docentes entrevistados manifiestan una percepción positiva del PCI en tanto política pública que procura la igualdad de oportunidades y la inclusión social a través de la entrega de netbooks a estudiantes y docentes. Incluso los docentes que no emplean las computadoras en sus clases, consideran que la política en sí misma es un acierto y es 
una iniciativa positiva para modernizar la educación y ampliar el acceso a las tecnologías digitales. Sin embargo, el análisis por estratos arroja divergencias relevantes. Tanto entre los docentes como entre los alumnos se visualiza la aprobación del impacto del plan en la escuela se incrementa en los estratos más bajos.

\subsection{Dimensión subjetiva}

En relación a las habilidades y a las destrezas vinculadas con las tecnologías digitales e Internet, encontramos que los alumnos previsiblemente se describen como altamente capacitados. Los alumnos efectivamente se perciben y son percibidos por los docentes como más hábiles que éstos últimos. Los referentes técnicos escolares (RTE) y los directivos son juzgados como competentes de modo razonablemente homogéneo entre docentes y alumnos.

Por otro lado, encontramos que con los docentes y RTE hay una divergencia entre sus habilidades imputadas y el pedido concreto de ayuda. Es decir, de acuerdo a los alumnos/as los docentes no son muy hábiles, pero se recurre mucho a ellos, posiblemente, porque son accesibles. Por el contrario, los RTE, conceptualizados como capaces, no son actores cercanos a la cotidianeidad de los alumnos. Sin embargo, el aspecto más relevante en términos de pedido de ayuda en relación a las tecnologías digitales es que un $14 \%$ de los docentes reconoce que pide ayuda a los alumnos. Más allá de la cifra, que puede estar subestimada, el punto es que esto subvierte la lógica de saber/poder asociada a la institución escolar industrial o disciplinaria. El saber, incluso el relativo a un objeto incorporado y formalizado por la institución, puede estar en manos del alumno/a.

Respecto a las habilidades de los docentes, incluso, debe alertarse una posible contradicción cuyas consecuencias deberían ser prevenidas. Muchos docentes tienden a sobrevalorar sus propias habilidades respecto de las de sus colegas, por lo tanto una buena porción de docentes podría no realizar capacitaciones porque se 
perciben a sí mismos cómo hábiles respecto de las tecnologías digitales e Internet, cuando para sus colegas y alumnos estos mismos docentes carecen de tal habilidad.

Una de los tópicos más controversiales en relación al $\mathrm{PCl}$ refiere a la medida en que éste favorece la mejora de los procesos de enseñanza aprendizaje específicamente en las aulas. Dos puntos son destacables al respecto.

El primero, sorprendente quizás, es que la opinión más positiva respecto del impacto pedagógico de las computadoras en las aulas proviene de los docentes. La mitad de ellos indica que los alumnos aprenden mejor en las clases en las que se usan. Esto contraría la opinión difundida según la cual los docentes sólo verían a las computadoras del PCl como un obstáculo para el desarrollo de sus labores. De cualquier forma, y notablemente, no hay una correspondencia entre esa representación y la utilización de las netbooks en clase por parte de los docentes -que las usan, como es bien sabido, raramente-.

El segundo, respecto a los procesos de enseñanza-aprendizaje mediados por las netbooks surge de que los docentes consideran que los alumnos aprenden mejor de lo que ellos enseñan. Esto puede significar al menos dos cosas: por un lado, que los alumnos realizan aprendizajes provechosos con las netbook en clase pero que exceden al docente. Esto es, que recurren a fuentes de conocimientos que no son impulsadas (o aun conocidas) por los docentes. Por ejemplo, alumnos que buscan información (que el docente juzga relevante) mediante modos que los docentes desconocen. Por otro lado, es factible que parte de la percepción docente de una mejora en el aprendizaje de los alumnos que no se debe a una mejora en la enseñanza docente surja de que los alumnos realizan actividades con las netbooks que, a la vez, los alejan de los docentes pero los conectan con la realización de dichas tareas. Por ejemplo, escuchar música con auriculares como un medio para concentrarse en el cumplimiento de actividades pedagógicas.

Hemos encontrado que en los procesos áulicos de enseñanza-aprendizaje juega un rol 
importante el acceso a Internet. Por un lado, hay una cierta asociación entre el funcionamiento de Internet y la dinámica pedagógica. Cuando Internet funciona bien, hay un incremento de quienes consideran que aprenden mejor con las netbooks. Sin embargo, esta lectura es parcial. $\mathrm{Si}$ se tiene en cuenta únicamente las representaciones de quienes efectivamente han usado las netbooks en clases encontramos que la incidencia del funcionamiento de Internet disminuye, de modo tal que, y este es un dato notable, hay $43 \%$ de alumnos que nunca han tenido Internet en la escuela, pero consideran que aprenden mejor en las clases en las que se utilizan las netbooks. Más aún, el análisis por estratos muestra que en estratos con niveles similares de funcionamiento de Internet (escaso o nulo), las representaciones respecto de la mejoría en el aprendizaje con las netbooks pueden variar sustancialmente. Es decir, el nivel de acceso incide en las representaciones aún cuando la situación efectiva (no funcionamiento de internet) sea similar. Algo parecido ocurre con las roturas de las netbooks: las mismas no explican por qué en un estrato con un bajo nivel de acceso (que tiene un nivel similar a otros de roturas) los alumnos tienden a considerar que las netbooks mejoran el aprendizaje en mayor medida que los alumnos de otros estratos.

Respecto a la meta-habilidad, generalmente denominada como multi-tasking, hemos encontrado que entre los alumnos, el $70 \%$ acepta que no puede llegar a 40 minutos continuos de concentración en un texto, más del 50\% no logra hacerlo por 20 minutos y un $25 \%$ no consigue alcanzar los 5 minutos de focalización lectora. Estos datos son difícilmente compatibles con la lógica del dispositivo escolar basado en la concentración en un único estímulo. Es decir, más allá de que haya netbooks, tabletas o celulares en las aulas o no, es claro que las transformaciones en la subjetividad propias del capitalismo informacional ya han tenido efecto: estos jóvenes ya tienen una capacidad (o incapacidad) moldeada. Pese a que, claro está, la institución escolar puede operar sobre ella, es importante no desconocerla, sino plantear alternativas 
pedagógicas que actúen en un sentido u otro (amoldándose a ella o combatiéndola) partiendo de reconocerla.

En cualquier caso, resulta notable que el rasgo de una atención volátil y efímera se repita, al menos tendencialmente, entre los docentes. No se trata, entonces, de un fenómeno acotado a determinadas generaciones, sino, posiblemente, de un aspecto que atraviesa a las sociedades contemporáneas. Eso, claro está, no merma las tensiones que supone esa modalidad para el dispositivo escolar.

\subsection{Dimensión intersubjetiva}

\subsubsection{Organizacional}

Un aspecto importante refiere a la medida en que las netbooks borronean la organización que separa el tiempo y espacio escolar del que no lo es, es decir si confirman el señalamiento del autonomismo italiano y, más en general, de los autores posestructuralistas en ese sentido.

En ese contexto, emergieron dos grupos importantes de estudiantes: aquellos que llevan las netbooks al menos dos veces a la semana (rondan el $47 \%$ de los encuestados) y aquellos que no la llevan casi nunca. Entre los primeros sobresale un uso lúdico o de entretenimiento marcando una clara penetración del ocio en la institución escolar. Por supuesto, el fenómeno no es completamente novedoso. Sin embargo, el cambio aquí radica en que esos usos surgen de una herramienta provista por la misma institución escolar, que tiene potencialidades educativas, y en la que la cantidad de información disponible, los usos posibles y las consecuencias de esos usos son cuantitativamente abrumadores e ingobernables por una escuela que pierde soberanía en su tiempo y espacio.

En segundo lugar, se halló que el uso de las netbooks fuera de la escuela con fines educativos tiene relevancia. La búsqueda de información, por caso, podría canalizarse a través de ellas en materias que no utilizan la computadora en clase. Este es un claro ejemplo del PCl penetrando en un proceso de enseñanza-aprendizaje pese a que la 
presencia de las netbooks en la escuela sea limitada. Esto debe contraponerse, no obstante, con el hecho de que cerca de la mitad de los estudiantes la usa menos de una vez por semana para tales tareas. Estos datos llevan a la discusión pedagógica respecto de si la prioridad está en aprovechar a las tecnologías digitales en el tiempo y espacio de la escuela, o de si incluso los usos estrictamente pedagógicos deben apuntar a concretarse en los hogares, en tiempos y espacios que exceden a los de la escuela.

Esto se ve respaldado por los datos de la encuesta que muestran que una parte no despreciable del vínculo entre actores de la comunidad (y más si incluimos los intercambios entre alumnos) sucede mediado por Internet. Por ejemplo, un $40 \%$ de los alumnos indica que tiene contacto con docentes, preceptores o directivos a través de Facebook o Whatsapp. Adicionalmente, debe mencionarse que esto ocurre enmarcado por plataformas privadas internacionales que no responden, en modo alguno, a las disposiciones de las carteras educativas locales ni al Estado Nacional. Efectivamente, se trata de una importante modificación en relación a la capacidad de la institución escolar para gobernar los intercambios comunicativos que ocurren en su seno. Vale insistir en que el PCI no es causa ni consecuencia de esta situación. La digitalización de los intercambios comunicativos es un fruto del capitalismo informacional, al igual que el propio PCI. Sin embargo, la inclusión de las tecnologías digitales por parte de la escuela tiende a favorecer estos procesos que la exceden.

Otro de los aspectos explorados en relación a la dinámica organizacional fue el de la autoridad. Encontramos que los docentes y alumnos se representan la obediencia a las instrucciones de los primeros hacia los segundos en niveles altos pero que, previsiblemente, este nivel de obediencia baja en lo tocante a las reglas acerca del uso de las tecnologías digitales e Internet.

\subsubsection{Reconocimiento}

Respecto de las redes de reconocimiento entre alumnos, la noción de "amigo" sigue 
aún anclada en los contactos presenciales. No obstante, en las escuelas en las que el $\mathrm{PCl}$ funciona mejor, las redes de reconocimiento virtuales, se incrementan, sin que esto se deba al funcionamiento de Internet en la escuela. Pero también las presenciales: en un estrato de bajo acceso en el que el $\mathrm{PCl}$ es percibido como funcionando relativamente bien, es donde se cuenta la menor cantidad de alumnos que considera que no tiene un grupo de amigos en la escuela. Así, el funcionamiento del PCl y las redes de reconocimiento, esto es, el capital social, parecen estar asociados, sin que haya un vínculo causal en un sentido u otro.

Respecto del reconocimiento de los docentes, éstos tienden a identificarse con la comunidad educativa y con quiénes tienen sus mismos gustos (dos modalidades usuales en el capitalismo informacional), en detrimento de otras variables (como las asociadas al trabajo, propias del capitalismo industrial). En relación a cómo se perciben como colectivo y como se sienten percibidos por los alumnos, los docentes destacan los aspectos extra-pedagógicos: "gente que realiza una tarea de contención social", "que no es suficientemente reconocida".

En cuanto a los RTE, hay un conjunto significativo de ellos que se percibe poco valorado en la escuela. Como se ha dicho, algunos de ellos desearían tener tareas más vinculadas a la articulación de lo técnico y lo pedagógico, y no solo la mera resolución de cuestiones burocráticas y técnicas. Otro conjunto de RTE se visualiza como figuras reconocidas en las escuelas; sin embargo, este reconocimiento no suele tener un correlato con las condiciones de trabajo (poco personal para encargarse de la gran cantidad y diversas tareas, precariedad en la contratación).

\subsubsection{Axiología}

En términos de valores expresados discursivamente, se destaca, tanto entre alumnos como entre docentes la presencia discursiva de valores "apolíneos", esto es, asociados a postergar goces inmediatos y pasatistas en pos de recompensas predecibles y futuras. Este predominio contrasta con la representación usual de los 
jóvenes como "dionisíacos".

En segundo lugar, hay una gran coincidencia entre ambos actores respecto del valor positivo asociado a la idea de descargar contenidos de Internet sin pagar por ellos. Nuevamente, el análisis por estratos nos muestra que allí donde el PCl funciona mejor, se encuentra coincidencias de sentido en la axiología de docentes y alumnos, y que se trata de actores que tienden a calificar más positivamente un conjunto de acciones polémicas referidas especialmente al uso de las tecnologías digitales.

Respecto de rankear valores, hay un altísimo nivel de coincidencia respecto del orden, e incluso de los porcentajes, con que los docentes y alumnos rankean valores propios. En líneas generales, se trata de valores tradicionales, propios del capitalismo industrial. La axiología posmoderna (no aburrirse, ser famoso, recibir atención, tener contactos) tiene escasas menciones. Notablemente, se produce una coincidencia entre docentes y alumnos del mismo sexo, lo cual muestra la fuerza transgeneracional -e incluso transclasistas- de las construcciones de género. Sin embargo, hay que agregar que cuando a los docentes se les pide que mencionen los valores que consideran que son los principales para los alumnos, estos sí les imputan aquellos que caracterizan a la posmodernidad.

\subsubsection{Normas}

Entre las normas asociadas a las netbooks, se registra un $32 \%$ de alumnos que sostienen que en su escuela no les permiten llevar la computadora los días que los docentes no la piden y un $40 \%$ que señala que tienen prohibido usar la computadora en clase.

En cuanto a las normas en general, hay un desacople entre la lectura que hacen distintos actores de las mismas escuelas (varones y mujeres, alumnos de edades distintas) respecto de qué está permitido y qué no lo está. Esto muestra, entre otras cosas, que especialmente respecto de las tecnologías digitales e Internet, no hay normas claras y unívocas aún dentro de cada escuela particular 
Cuando se consulta de manera abierta por normas a modificar, casi un tercio de los alumnos refiere a aquellas vinculadas con el uso de las tecnologías digitales, pero sólo lo hace un $5 \%$ de los docentes. Hay aquí un desencuentro relevante del que conviene tomar nota.

\subsubsection{Lenguaje}

Un $40 \%$ tanto de alumnos como de docentes señala que hay expresiones que el otro grupo desconoce o no puede interpretar. Es decir, la capacidad de comprensión del otro se representa de un mismo modo, limitada.

Asimismo, tanto los docentes como los alumnos juzgan sus capacidades para comprender los términos del otro actor de un modo superior a como las evalúa el grupo emisor. Esto podría ser una fuente importante de limitaciones en los flujos cognitivos: la creencia de que se entiende algo que quien lo dice considera que no se ha comprendido.

A diferencia de lo que ocurría con las normas, las discrepancias lingüísticas, más allá de su incidencia en una circulación efectiva de los flujos comunicativos, no parecen estar signadas por el PCI o, más genéricamente, las tecnologías digitales e Internet.

\subsection{Dimensión objetiva}

\subsubsection{Infraestructura}

Aunque la tendencia es conocida, es relevante señalar que algo más de la mitad de los alumnos (57\%) manifestó que Internet no anda nunca o casi nunca. Cerca de un cuarto (27\%) señaló que anda en algunos lugares (aunque no en el aula), y apenas un 15\% afirmó que en su escuela Internet anda siempre o casi siempre y en todos lados. Más aún, registra entre quienes señalaron que Internet anda en algunos lugares o en todos lados (42,6\% del total de alumnos), 3 de cada 4 manifestaron que la conexión es lenta o inestable.

\subsubsection{Hardware}

Consultados por cómo son las netbooks del PCI, tanto alumnos como docentes las 
evalúan mayoritariamente en forma positiva. Quizás llamativamente, se observa una valoración más favorable de los docentes que de los alumnos (64\% de evaluaciones positivas frente a $51 \%$ de los segundos).

También son conocidos pero relevantes los datos respecto de la rotura de las netbooks: La mitad de los alumnos consultados señaló que alguna vez se les rompió. Entre ellos, sólo 1 de cada 10 consultados consideró que su netbook fue arreglada en forma rápida.

Respecto de la importancia de las netbooks del PCl en relación a otras computadoras del hogar, hallamos que es la única computadora del hogar para un $10 \%$ de los alumnos.

Sin embargo, este dato presenta divergencias por estrato: en los estratos con menores niveles de acceso la cifra llega a un cuarto de los alumnos.

Entre ellos encontramos la cifra más alta respecto de la importancia dada a la netbook del PCl entre los alumnos y la más baja entre los docentes. La novedad y necesidad de cuidar la computadora por parte de los alumnos combinada con la presencia de tecnologías digitales en los hogares concretos de los docentes (es decir, familiarizados con ellas) podría ser un elemento directamente relacionado con una dinámica escolar que aprovecha de mejor modo al PCl.

\subsubsection{Software}

Docentes y alumnos manifiestan utilizar Windows como sistema operativo de manera casi unánime. Solo un $2 \%$ de la muestra de alumnos menciona Huayra u otras distribuciones de Linux. En el caso de docentes, asciende a un escaso 4.5\%.

Respecto de aplicaciones específicas, confirmamos resultados de otras investigaciones: las aplicaciones vinculadas a Internet son las más relevantes. Facebook domina de modo amplio, superando incluso a Google. Con porcentajes exiguos, al final, encontramos a los programas educativos del $\mathrm{PCl}$. Los de programación, en particular, son los últimos del ranking que establecimos. 
Sin embargo, tenemos variaciones por estrato. En los más bajos se realiza un uso mucho mayor de los software educativos que en cualquier otro estrato y se hace un uso algo mayor de las herramientas de manejo de archivos online y de los programas multimedia offline.

\subsubsection{Contenidos}

Respecto de los contenidos, los alumnos se destacan, claramente, en el consumo de música. Los docentes, en cambio, señalan principalmente el consumo de libros y otros textos, aunque en todas las categorías presentan valores parejos.

Entre los estudiantes de escuelas técnicas se evidencia cierto contrapunto: mientras algunos valoran que la netbook trae programas interesantes para sus especialidades, otros reniegan de la falta de capacidad del hardware para instalar programas específicos muy relevantes para sus materias.

\section{Conclusiones}

En síntesis, los principales hallazgos de nuestra investigación han sido los siguientes: En términos generales, el $\mathrm{PCl}$ tiende a ser representado como equivalente a las netbooks, desconociendo sus múltiples aspectos. Este fenómeno de sinécdoque tecnológica es mayor allí donde el PCl funciona peor y menor donde funciona mejor. Sin embargo, entre sectores excluidos en términos de acceso a la información digital y de infraestructura urbana, el PCI es valorado no sólo en su aspecto de inclusión digital, sino en relación a las mejoras pedagógicas en las escuelas. Los docentes tienen opiniones positivas respecto del impacto pedagógico del $\mathrm{PCl}$, incluso superiores a las de los alumnos.

En lo tocante a los conocimientos subjetivos, puede decirse que: 1. los alumnos se perciben y son percibidos por los docentes como más hábiles en el manejo de las tecnologías digitales que éstos últimos. 2. En relación a las destrezas de los alumnos, también resultó que entre ellos/as, el $70 \%$ acepta que no puede llegar a 40 minutos 
continuos de concentración en un texto, más del $50 \%$ no logra hacerlo por 20 minutos y un $25 \%$ no consigue alcanzar los 5 minutos de focalización lectora. Estos datos son difícilmente compatibles con la lógica del dispositivo escolar basado en la concentración en un único estímulo.

En cuanto a los conocimientos de soporte intersubjetivo, los siguientes son, tal vez, los principales hallazgos. En términos organizacionales, la mitad de los alumnos lleva la netbook a la escuela una vez por semana o menos. Un $32 \%$ de alumnos que sostienen que en su escuela no les permiten llevar la computadora los días que los docentes no la piden y un $40 \%$ que señala que tienen prohibido usar la computadora en clase. Los usos que se hacen de las netbooks en la escuela por fuera del tiempo de clase y en el hogar con fines pedagógicos son muy relevantes.

En relación a las redes de reconocimientos, un $40 \%$ de los alumnos tiene vínculos con docentes, preceptores o directivos mediante Facebook o Whatsapp. Esto refleja de una importante modificación en relación a la capacidad de la institución escolar para gobernar los intercambios comunicativos que ocurren en su seno. Asimismo, El funcionamiento del PCI parece estar asociado al capital social: funciona mejor donde hay más densidad vincular y viceversa.

Respecto de las normas a modificar, casi un tercio de los alumnos refiere a aquellas vinculadas con el uso de las tecnologías digitales, pero sólo lo hace un $5 \%$ de los docentes. Hay aquí un desencuentro relevante del que conviene tomar nota.

En cuanto a los conocimientos objetivos, se presentan las siguientes conclusiones. En las representaciones de alumnos y docentes, el funcionamiento de Internet colabora con los procesos de enseñanza aprendizaje. No obstante, hay $43 \%$ de alumnos que nunca han tenido Internet en la escuela, pero consideran que aprenden mejor en las clases en las que se utilizan las netbooks.

En ese sentido, algo más de la mitad de los alumnos (57\%) manifestó que Internet no anda nunca o casi nunca en su escuela. Cerca de un cuarto (27\%) señaló que anda en 
algunos lugares (aunque no en el aula), y apenas un 15\% afirmó que en su escuela Internet anda siempre o casi siempre y en todos lados. Entre quienes señalaron que Internet anda en algunos lugares o en todos lados (42,6\% del total de alumnos), 3 de cada 4 manifestaron que la conexión es lenta o inestable.

La mitad de los alumnos consultados señaló que alguna vez se les rompió la netbook. Entre ellos, sólo 1 de cada 10 consultados consideró que su netbook fue arreglada en forma rápida.

Docentes y alumnos manifiestan utilizar Windows como sistema operativo de manera casi unánime. Solo un $2 \%$ de la muestra de alumnos menciona Huayra u otras distribuciones de Linux. En el caso de docentes, asciende a un escaso 4.5\%.

En base a los hallazgos descriptos, a continuación se ofrece un conjunto de recomendaciones tendientes a explotar las potencialidades detectadas y corregir 0 reforzar aquellos aspectos que operan como un obstáculo para la plena y efectiva implementación del PCI en la escuela.

\section{Dimensión subjetiva}

La discrepancia entre las percepciones de los docentes en relación a las tecnologías digitales respecto de la propia habilidad y la percibida por otros actores sugiere la necesidad de cierta clase no sólo de capacitación, que sigue siendo extremadamente necesaria, sino también de evaluación de destrezas informacionales mínimas. Naturalmente, la viabilidad de esta recomendación es opinable, pero ello no la vuelve menos necesaria.

Parte de esas capacitaciones debe dedicarse a usos pedagógicos de las netbooks en dos situaciones que han sido insuficientemente estudiadas: sin internet y en el hogar.

Es necesario desarrollar capacidades docentes para estimular usos conducentes de las netbooks en esos contextos.

Luego, ante la dificultad de concentración prolongada en un único estímulo es necesario definir políticas en un sentido que esta investigación no puede definir: 
¿adecuar la enseñanza mediante modalidades de estímulos simultáneos o focalizarse en intentar enseñar el viejo hábito de la racionalidad focal? En cualquiera de las opciones, es necesario actuar coordinadamente en distintas asignaturas y a nivel institucional, alineando normas, valores, tecnologías y destrezas de los actores.

Dimensión intersubjetiva.

\section{Organización}

La escuela ya es una institución que trasciende su tiempo y espacio. Ha de asumirse como tal en términos explícitos y a la vez, actuar en función de su soberanía limitada en los nuevos tiempos y territorios sobre los que la despliegan los flujos informacionales. Es necesario adoptar regulaciones sobre esa organización extendida en vez de mostrar indiferencia hacia ella. Por ejemplo, las relaciones escolares y no escolares de los miembros de la comunidad, particularmente docentes y alumnos, a través de Facebook, no debería ser un fenómeno ajeno a la institución educativa. Idealmente, el desarrollo de plataformas específicas (del estado o de actores sin fines de lucro no estatales), soberanas y signadas por valores específicos, podría canalizar esas interacciones de un modo virtuoso.

\section{Normas}

Se recomienda realizar un análisis detallado de las actuales prohibiciones existentes respecto a los usos de las tecnologías digitales en las escuelas. Muchas veces, los directivos y docentes se ven forzados a censurar ciertos usos debido a que así lo fija la ley. Sin embargo, algunos de estos usos son altamente valorados por los estudiantes y, en muchos casos, por los propios docentes, ya que abren distintas instancias y modalidades de participación y atención en las clases (como hemos visto en el caso de escuchar música con auriculares.

Asimismo, parece importante regular de modo explícito distintas conductas que no son interpretadas del mismo modo -en términos de estar permitidas o no- por los actores de las mismas escuelas. 


\section{Reconocimiento}

La figura sobre la que se debe actuar en este plano prioritariamente es la del Referente Técnico Escolar. En este sentido se recomienda subsanar las condiciones de contratación y remuneración de aquellos que desempeñan una función clave en la implementación del PCl.

Los RTE han generado conocimientos sobre su función que circulan por vías "nooficiales" como páginas de Facebook, canales de Youtube, etc. Se recomienda que los diseñadores de la política pública recuperen esas experiencias tanto para monitorear la implementación del PCl, diagnosticar posibles inconvenientes y, en consecuencia, promover soluciones efectivas.

Dado que los RTE son conceptualizados como capaces tanto por alumnos como por docentes pero que no son consultados frecuentemente porque no son actores cercanos a la cotidianeidad de los alumnos (en muchos casos directamente se los desconoce), entendemos que la revalorización de sus cargos y funciones podría redundar en una mejora sustancial en la solución no solo de problemas técnicos sino también en la promoción de usos habilidosos en las clases.

\section{Valores}

La idea compartida por docentes y alumnos respecto de que es correcto descargar contenidos sin pagar por ellos merece acciones estatales. No para reprimir la vocación de descargar de modo gratuito de Internet contenidos o software, pero sí para orientar respecto de cómo deben canalizarse esos valores. Por ejemplo, brindar información respecto de las licencias libres, del software libre de los contenidos estatales en dominio público. Esto es, el valor de que el acceso al conocimiento es libre debe preservarse y cultivarse, pero debe orientarse hacia modalidades eficaces para su cumplimiento, distinguiendo diversas situaciones.

\section{Dimensión objetiva}

En términos de infraestructura, una primera recomendación es movilizar todos los 
recursos necesarios para universalizar la conexión a Internet en las escuelas de todo el país. Esto no debe opacar el hecho de que aún en caso de ausencia de Internet las posibilidades pedagógicas del PCI son importantes. Esto es, no debe aceptarse como excusa del no uso de las netbook en clase o fuera de ella con fines educativos a esa ausencia de Internet.

En relación al hardware, es importante mejorar el circuito de reparación de las netbooks, reduciendo los tiempos.

Respecto del software, es fundamental difundir las características de Huayra en particular y del software libre en general entre alumnos, docentes, directivos y RTE.

Del mismo modo, es importante favorecer la utilización de los softwares educativos del propio $\mathrm{PCl}$ que son aún muy poco explotados.

\section{Referencias}

Alessio, A. M., Nottaris, D. B. y Rodriguez, M. I. (2012). Desafíos en la articulación del eje universitario escuelas medias. ExT: Revista de Extensión de la UNC, 2(2).

Benítez Larghi, S. (2013). Los sentidos de las políticas públicas tendientes a la universalización del acceso a las tecnologías digitales: el caso del Programa Conectar Igualdad. Cuestiones de sociología, (9).

Benítez Larghi, S., Lemus, M. y Welschinger, N. (2015). Conectad@s desde la escuela. Percepciones y apreciaciones de los estudiantes sobre el espacio escolar a partir de la implementación del Programa Conectar Igualdad. En Silvia Lago Martínez (Coord.) De tecnologías digitales, Internet y educación formal. Retratos de los planes "una computadora, un alumno". Buenos Aires: Teseo.

Benítez Larghi, S., Fontecoba, A. y Lemus, M. (2014). Bibliografía comentada desde la perspectiva de la evaluación de los modelos Uno a Uno en Latinoamérica, Revista Versión, Estudios de Comunicación y Política, (34). 
Bogado, A. G. (2013). Representaciones sociales de estudiantes secundarios sobre el proceso de inclusión digital a partir de la implementación del programa Conectar Igualdad. Virtualidad, Educación y Ciencia, (7).

Casablancas, S. (2014). La cuestión de la formación docente en los modelos 1 a 1. E caso del proyecto piloto Escuelas de innovación, dentro del programa «Conectar igualdad» (República Argentina). Educar, 50(1).

Castells, M. (1999) La Era de la Información: Economía, Sociedad y Cultura: La sociedad Red. México: Siglo XXI.

Consejo Federal de Educación (2010). Las políticas de inclusión digital educativa. El Programa Conectar Igualdad, Anexo I de la Resolución 123 del Consejo Federal.

Da Silva Ramos, M. y López Gallego, L. (2014). Pensando el "Plan Ceibal" desde la perspectiva de la Acción Pública y la Teoría del Actor-Red. Athenea Digital, 14(1). doi: http://dx.doi.org/10.5565/rev/athenead/v14n1.939

De La Fuente, P., Guérin, A. I., Güida, M. C., Eugenio, M., y Pérez Antelaf, M. E. (2011). Potencialidades de las NTICs en la educación: la experiencia del programa conectar igualdad.com.ar. En Jornadas Patagónicas de estudios sociales sobre Internet y tecnologías de la comunicación. Comodoro Rivadavia: Universidad Nacional de la Patagonia San Juan Bosco.

Dughera, L. (2013a). El Desembarco del modelo "Una computadora, un alumno" en las escuelas primarias pioneras comunes de la Ciudad Autónoma de Buenos Aires (2010-2011). Un análisis desagregado de los actores, las relaciones problemassoluciones y las regulaciones que se co-construyen en el Plan Sarmiento (Tesis de Maestría). Universidad Nacional de Quilmes, Buenos Aires, Argentina.

Dughera, L. (2013b). De tecnologías digitales, docentes y tensiones. La capacitación, ¿un factor más para disminuir la brecha digital?. Revista TecCom Studies Estudios de Tecnología y Comunicación, (5). Madrid: Universidad Complutense 
de Madrid.

Dussel, I. (2014) Programas educativos de inclusión digital. Una reflexión desde la Teoría del Actor en Red sobre la experiencia de Conectar Igualdad (Argentina), Versión. Estudios de Comunicación y Política, (34).

Dussel, I. (2011). Aprender y enseñar en la cultura digital. Documento Básico, VII Foro Latinoamericano de Educación. Buenos Aires: Fundación Santillana.

Fontdevila, P. (2011). Estudio de caso: Conectar Igualdad, Revista Iberoamericana de Ciencia, Tecnología y Sociedad, 6(18).

Grebnicoff, D., (2011). Estrategia político-pedagógica y marco normativo del Programa Conectar Igualdad. Buenos Aires: Ministerio de Educación de la Nación.

Gruszycki, A. E., Oteiza, L. N., y Maras, P. M. (2012). GeoGebra se conecta a la igualdad. ExT: Revista de Extensión de la UNC, 2(2).

Gvirtz, S. y Necuzzi, C. (comp.) (2011). Educación y tecnologías. Las voces de los expertos. Conectar Igualdad. Buenos Aires: Anses.

Jodelet, D. (1986). La representación social: fenómenos, conceptos y teoría. En S. Moscovici, Psicología Social II. Pensamiento y vida social. Psicología social y problemas sociales. Barcelona: Paidós.

Lago Martínez, S., Marotias, A. y Amado, S. (2012). Inclusión digital en la educación pública argentina. El Programa Conectar Igualdad, Revista Educación y Pedagogía, 24(62).

Lessig, L. (1999). Code and other laws of cyberspace. Nueva York: Basic Books.

Lucangioli, A. (2013). Jóvenes y medios: los desafíos de la integración de las TIC en el sistema educativo. En Kaplan, C. V. y Bracchi C.C. (comp.), Imágenes y discursos sobre los jóvenes. La Plata: DGCyE, UNLP.

Lugo, M. T. y Kelly, V. (2011). El modelo 1 a 1: un compromiso por la calidad y la igualdad educativa: la gestión de las tic en la escuela secundaria: nuevos formatos institucionales. Buenos Aires: Ministerio de Educación de la Nación. 
Ministerio de Educación de la Argentina (2012). Historias uno a uno. Imágenes y testimonios de Conectar Igualdad. Buenos Aires: Ministerio de Educación de la Nación .

Ministerio de Educación de la Argentina (2011). Nuevas voces, nuevos escenarios. Estudios evaluativos sobre el Programa Conectar Igualdad. Buenos Aires: Ministerio de Educación de la Nación.

Nosiglia, M. C., y Norbis, L. B. (2013). Las Políticas de Inclusión de Tecnologías en la Enseñanza: una Comparación entre los casos de Argentina y Uruguay. Índice, (25).

Rivoir, A. (2014). Brecha digital e inclusión social, contribuciones y dilemas de las políticas 1 a 1. El caso de Ceibal en Uruguay. Revista Razón y Palabra, (87).

Ros, C. C., Cimolai, S., González, D., Masnatta, M., Montero, J., Ochoa De La Fuente, L., y Segal, A. (2014). Inclusión digital y prácticas de enseñanza en el marco del programa Conectar Igualdad para la formación docente de nivel secundario. Buenos Aires: Ministerio de Educación de la Nación.

Sagol, C. (2011). El modelo 1 a 1: notas para comenzar. Buenos Aires: Ministerio de Educación de la Nación.

Spinazzola, M. y Thüer, S. (2013). El Diseño Universal en la producción de materiales educativos: El caso Conectar Igualdad. En VI Encuentro Panamericano de Comunicación, Córdoba, Argentina. Recuperado de: http://www.publicacioncompanam2013.eci.unc.edu.ar/files/companam/ponencia s/Escenarios\%20digitales/-Unlicensed-Escenarios-

Digitles_Spinazzola\%20Thuer.pdf

Vacchieri, A. (2013). Las políticas TIC en América Latina. Caso Argentina. Buenos Aires: UNICEF.

Vercelli, A. (2006). Aprender la Libertad: el diseño del entorno educativa y la producción colaborativa de los contenidos básicos comunes. Buenos Aires: 
Aprender la Libertad.

Verdún, N., y Gutiérrez, C. (2014). Saberes Docentes y Tecnologías Emergentes en la Escuela Secundaria: Enciclomedia (México, 2006) y Conectar Igualdad (Argentina, 2011). Revista Latinoamericana de Educación Comparada, 5(5).

Zukerfeld, M. (2014a) Todo lo que Ud. Quiso saber sobre Internet pero nunca se atrevió a googlear. Hipertextos: Capitalismo, Técnica y Sociedad en debate, 2(2). Buenos Aires: Universidad de Buenos Aires.

Zukerfeld, M. (2014b). Capitalismo Cognitivo y Educación: Aproximaciones desde el materialismo cognitivo. En Ramírez, Bula y Rueda, Rocío (Eds.), Cibercultura, capitalismo cognitivo y educación -Conversaciones y re(di)sonancias. Bogotá: Universidad Pedagógica Nacional.

Zukerfeld, M. (2017). Knowledge in the Age of Digital Capitalism: An Introduction to Cognitive Materialism. Londres: University of Westminster Press.

\section{Formato de citación}

Zukerfeld M. (2017). Inclusión, escuela y conocimientos: Elementos para un análisis materialista del programa Conectar Igualdad en las escuelas argentinas. Psicología, Conocimiento y Sociedad, 7(2), 134-161. Disponible en: http://revista.psico.edu.uy/ 